\title{
KARAKTER GAJAH MADA: SIMBOL KEJAYAAN MAJAPAHIT
}

\author{
Ni'mah Alpiyah ${ }^{1)}$, Iis Purnengsih ${ }^{2)}$ \\ Program Studi Desain Komunikasi Visual, \\ Fakultas Bahasa dan Seni, Universitas Indraprasta PGRI \\ Jl. Nangka No. 58 C, Tanjung Barat, Jakarta 12530, Indonesia \\ Ialfiyah.nimah@gmail.com,," iispurningsih@gmail.com
}

\begin{abstract}
Abstrak
Kerajaan Majapahit merupakan sebuah kerajaan tertua di Indonesia, Berdiri tepatnya di daerah Tarik, Sidoarjdo Jawa Timur. Berjayanya Kerajaan Majapahit yaitu pada masa kepemimpinan Raja Hayam Wuruk, berkat jasa Mahapatih Gajah Mada dalam sumpahnya yang terkenal dengan sumpah Palapa. Karena itu Mahapatih Gajah Mada adalah tokoh sejarah Kerajaan Majapahit yang memiliki pengaruh besar dalam memperluas kekuatan Kerajaan Majapahit. Gagasannya yaitu menyatukan wilayah - wilayah di Nusantara. Artikel ini akan membahas perancangan visual karakter Gajah Mada dalam film animasi "Kejayaan Majapahit" dengan tujuan untuk mengetahui karakter visual Gajah Mada sebagai Mahapatih yang berpengaruh di Kerajaan Majapahit. Analisis visual artikel ini menggunakan analisis Kualitiatif, sehingga dengan analisis ini dapat diketahui karakter visual Gajah Mada sesungguhnya. Dan film animasi dibuat sebagai media mendukung agar karakter visual Gajah Mada lebih menarik perhatian khususnya audience yaitu remaja.
\end{abstract}

Kata Kunci: Visual Karakter, Keajayaan Majapahit, Gajah Mada.

\begin{abstract}
The Majapahit Kingdom is the oldest kingdom in Indonesia, established precisely in the area of Tarik, Sidoarjdo, East Java. The success of the Majapahit Kingdom was during the reign of King Hayam Wuruk, thanks to the services of Mahapatih Gajah Mada in his oath which was famous for Palapa's oath. Therefore Mahapatih Gajah Mada is a historical figure of the Majapahit Kingdom who had a major influence in expanding the power of the Majapahit Kingdom. The idea is to bring together regions in the archipelago. This article will discuss the visual design of the Gajah Mada character in the animated film "Majapahit Glory" with the aim to find out the visual character of Gajah Mada as an influential Mahapatih in the Majapahit Kingdom. Visual analysis of this article uses qualitative analysis so that with this analysis can be seen the actual visual character of Gajah Mada. And animated films are made as a media to support Gajah Mada's visual character to attract more attention, especially the audience, namely teenagers.
\end{abstract}

Keywords: Kingdom, Majapahit, Empire

\section{PENDAHULUAN}

Majapahit merupakan nama yang tidak asing lagi dalam perjalanan panjang sejarah Indonesia, terhitung sebagai kerajaan terlama berdiri di Nusantara. Kerajaan Majapahit berdiri pada tahun 1293 M hingga 1500 M dan berpusat di daerah Tarik, Sidoarjo, Jawa Timur.

Keistimewaan dari Majapahit yaitu menggambarkan sebuah pemerintahan kerajaan yang meliputi sejarah kemegahan, kekayaan, budaya, pemberontakan, kejayaan, perang saudara, dan 
kehancuran. Dan Majapahit merupakan kerajaan yang berkembang dalam bidang politik, perekonomian, dan perdagangan global.

Gagasan menyatukan wilayah - wilayah Nusantara muncul pada masa kejayaan Majapahit, sebuah kerajaan yang dibangun oleh Raden Wijaya. Masa kejayaan Majapahit yaitu pada masa pemerintahan Hayam Wuruk.

Kejayaan Majapahit baru muncul puncaknya dan mulai melebarkan pengaruhnya ke luar Jawa, yaitu ke Bali, pada masa pemerintahan Tribhuwanna Wijayatunggadewi $(1328$ - $1350 \mathrm{M})$, sebagai ibunda dari Hayam Wuruk, Pada waktu itu penyerangan di daerah Bali dipimpin oleh Mahapatih Gajah Mada, bersama saudara sang ratu dari Minangkabau, yaitu Arya Wangsadhiraja Adityawarman (Munandar, 2008:1).

Dalam perkembangan sejarah bangsa Indonesia, Kerajaan Majapahit tidak bisa lepas dari sejarah kerajaan Singasari. Dari sini dapat disimpulkan bahwa secara garis keturunanan, pendiri kerajaan Majapahit merupakan pewaris kekuasaan kerajaan Singasari yang sebelumnya runtuh. Dengan dibukanya hutan di Desa Tarik sebagai lahan untuk mendirikan kerajaan Majapahit oleh Raden Wijaya, dan tujuan ini sebagai usaha menarik simpati penduduk sekitarnya, sehingga ia banyak disukai oleh para penduduk sekitarnya, Banyak penduduk sekitar yang ingin bertempat tinggal di Majapahit saat itu.

Gajah Mada adalah Mahapatih Amangkubumi yang berjaya menyatukan Nusantara. Hal itu tertuang dalam sumpah Palapa yang diucapkan oleh Mahapatih Gajah Mada dan dicatat dalam Serat Pararaton. Di situ dapat ditemukan bahwa 10 wilayah di Nusantara yang menjadi sasaran harus mengakui kejayaan Majapahit, yaitu Gurun, Seran, Tanjung pura, Haru, Pahang, Dompo, Bali, Sunda, Palembang, dan Tumasik.

Dengan demikian, peranan dan pengaruh Gajah Mada saat itu cukup besar di Majapahit. Sumpah Palapa Gajah Mada merupakan penerus gagasan Nusantara Kertanegara tersebut terbukti berhasil karena dapat menaklukan seluruh wilayah - wilayah Nusantara.

Berdasarkan hasil survei, tidak sedikit audience yang tidak mengetahui sosok/figure Gajah Mada. Karena itu, dalam artikel ini akan membahas perancangan karakter visual Gajah Mada dengan Tujuan sebagai media pembelajaran sehingga audience mengenal karakter visual Gajah Mada sebagai Mahapatih yang berpengaruh bagi kerajaan Majapahit.

Untuk mendukung karakter visual Gajah Mada, perlu perancangan lain sehingga audience selain mengetahui sosok Gajah Mada, juga dapat mengetahui sejarah "Kejayaan Majapahit". Dalam hal ini penulis nantinya akan membuat film animasi sebagai media pendukung karakter visual Gajah Mada. Dengan menampilkan konsep film animasi 2D, sebab media film animasi dapat menjadi daya tarik audience dan memiliki nilai yang berbeda dalam menyampaikan sebuah informasi terkait sejarah.

Film biasanya dipakai untuk merekam suatu keadaan atau menyampaikan sesuatu. Film digunakan untuk memenuhi suatu kebutuhan umum yaitu dengan mengomunikasikan suatu gagasan, pesan atau kenyataan. Karena keunikan dimensinya dan karena sifat hiburannya, film telah diterima sebagai salah satu media audio visual yang paling popular dan paling digemari oleh kalangan anak - anak maupun remaja. Karena itu, juga dianggap sebagai media yang paling efektif. Keinginan manusia untuk membuat gambar atau santiran (image) yang hidup dan bergerak sebagai perantara dari pengungkapan (expression) mereka, merupakan perwujudan dari bentuk animasi yang hidup berkembang.

Menurut Wojowasito dalam Syahfitri (2011), kata "animasi" itu sendiri sebenarnya penyesuaian dari kata "animation" yang berasal dari kata dasar to animate dalam kamus umum Inggris - Indonesia berarti menghidupkan, menggerakkan benda mati. Suatu benda mati diberikan dorongan kekuatan, semangat dan emosi untuk menjadi hidup dan bergerak berkesan hidup.

Dapat dikatakan bahwa animasi merupakan suatu media yang lahir dari dua konversi atau disiplin, yaiu film dan gambar. Untuk dapat megerti dan memakai Teknik animasi, dua konversi tersebut harus dipahami dan dimengerti. (Syahfitri, 2011). 


\section{METODE PENELITIAN}

Metode yang digunakan pada penelitian ini adalah metode penelitian kualitatif. Penelitian melakukan observasi secara langsung dan wawancara. Observasi langsung, yaitu dengan mengunjungi Situs Trowulan, merupakan daerah istimewa Jawa Timur, khususnya di Mojokerto. Pada tanggal 13-14 Mei 2018. Kemudian Peneliti melakukan wawancara dengan narasumber yang kompeten pada situs kejayaan Majapahit, yaitu dengan Ibu Yanti, S. Hum. selaku ketua Arkeolog di Museum Trowulan. Selain itu, peneliti melakukan wawancara dengan remaja sebagai target audience rentang usia 11-18 tahun.

Diperolehnya data tentang sejarah kejayaan Kerajaan Majapahit. Informasi juga dapat diperoleh melalui penelusuran literatur. Setelah melakukan proses analisis terhadap fakta - fakta yang ada, peneliti kemudian menyajikan dalam bentuk tulisan. Peneliti berusaha menyajikan hasil penelitian dengan gaya bahasa yang menarik dan komunikatif. Dapat diartikan bahwa penelitian historis adalah cara yang digunakan untuk menyelesaikan suatu masalah dengan menganalisis secara kritis peninggalan masa lampau berupa data fakta ataupun dokumen yang disusun secara sistematis, dari evaluasi yang objektif dari data yang berhubungan dengan kejadian masa lampau untuk memahami kejadian baik masa lampau, maupun masa sekarang.

\section{HASIL DAN PEMBAHASAN}

Kerajaan Majapahit merupakan sebuah kerajaan yang tersohor di tanah Jawa dan Nusantara. Ketersohoran namanya tidak lepas dengan peran Mahapatih Patih Amangkubhumi Gajah Mada semasa pemerintahan Hayam Wuruk. Mampu menjadikan Majapahit sebagai pusat kekuasaan dari seluruh wilayah Nusantara (Adji, 2013).

Menurut Masmada \& Reny, dalam Susilo \& Sofiarini (2018). Zaman kejayaan kerajaan Majapahit terkenal dengan masa pemerintahan Hayam Wuruk, yang merupakan raja keempat Majapahit. Hayam Wuruk Lahir pada tahun 1334, beberapa bulan sebelum Gajah Mada dikukuhkan sebagai Mahapatih Amangkubhumi. Pada saat Gajah Mada mengucapkan sumpah sakral Amukti Palapa, bayi Hayam Wuruk baru saja menikmati udara Majapahit. Di tangannyalah kemudian seluruh perairan nusantara bersatu menentang penjajahan bangsa asing, terutama Tiongkok.

Masa kejayaan Majapahit berlangsung dalam era pemerintahan Hayam Wuruk. Masa sebelumnya, kejayaan Majapahit baru mulai mendaki kearah puncaknya. Pada masa pemerintahan Ratu Tribhuwana Wijayatunggadewi (1328 - 1350 M), ibunda Hayam Wuruk, Majapahit mulai melebarkan pengaruhnya keluar pulau Jawa antara lain ke Bali. Penyerangan ke Bali dipimpin oleh Mahapatih Gajah Mada dan saudara sang ratu yaitu Arya Wangsadhiraja Adityawarman, pada waktu itu. Puncak kejayaan Majapahit yang ditandai dengan terwujudnya gagasan penyatuan wilayah - wilayah Nusantara.

Masa pemerintahan Hayam Wuruk dianggap masa kejayaan Majapahit karena tidak ada konflik internal ataupun eksternal dengan daerah - daerah lainnya, kecuali peristiwa Pasundan Bubat di tahun 1357 M. (Munandar, 2008). Daerah - daerah pulau Jawa (Nusantara) banyak yang mengakui kebesaran Majapahit, hal ini terlihat dengan dikirimkannya utusan setiap tahun ke istana Hayam Wuruk. Pengiriman utusan atau upeti ke Majapahit bukan akibat penyerangan atas daerah - daerah tersebut, melainkan karena perjalanan muhibah armada dagang Majapahit yang megah ke daerah - daerah. Mereka lalu mengagumi kebesaran majapahit sehingga darah - daerah rela mengirimkan upetinya (Munandar, 2008).

Kebesaran Majapahit merupakan sebagai negara pemersatu bangsa, nusantara raya, dikenal hampir di seluruh mancanegara pada zamannya dari tahun 1293 sampai 1478. Kemajuan kerajaan Majapahit dalam bidang perekonomian, sosial, budaya dan politik dapat menarik perhatian beberapa negara sahabat, Kebesaran Majapahit, juga dapat disebut sebagai kebesaran Gajah Mada, seorang Patih yang telah mengabdi kepada tiga kepemimpinan pemerintahan selama lebih dari tiga puluh tahun.

Gajah Mada mempunyai peranan sebagai pengawal kementerian, Patih Majapahit adalah Patih yang paling tinggi di dalam keseluruhan kerajaan untuk menggalakkan kebajikan negeri, dibentuk beberapa pusat jabatan, yang mengurusi urusan upeti dan pemeliharaan jalan. Keraton, 
candi, dan gedung - gedung pemerintahan diperkenalkan oleh jabatan umum. Dengan istimewa dibentuk jabatan untuk mementingkan urusan kesehatan, pengairan, lalu lintas, pertanian, hasil bumi, perdagangan, kesejahteraan umum. Berikut kutipan Serat Pararaton yang menjelaskan sumpah Gajah Mada. (Nurhayati, 2018).

Menurut Pinuluh, Esa, \& Damar, dalam Susilo \& Sofiarini (2018). Masyarakat Majapahit umumnya merupakan masyarakat yang majemuk. Wilayah kerajaan Majapahit yang sangat luas, dengan segala karakteristik wilayahnya, menjadikan Majapahit memiliki keragaman yang ditentukan oleh banyak hal, wilayah di pedalaman yang bersendikan agraris, akan memiliki pola kebudayaan yang berbeda degan daerah pantai yang bersendikan perdagangan. Masyarakat pedalaman lebih bersifat tertutup dengan kebudayaan suklus (berputar tetap).

Sementara masyarakat pantai sering berhubungan dengan masyarakat asing, lebih bersifat terbuka terhadap hal - hal baru. Kehidupan keagamaan Majapahi menunjukkan pula hubungan dengan sendi - sendi toleransi yang kuat. Majapahit mengakui dan menghormati dua agama besar saat itu, yaitu Hindu dan Buddha, dalam bentuk pengangkatan pejabat keagamaan dalam struktur pemerintahannya.

\section{Mendesain elemen visual karakter Gajah Mada}

Gajah Mada adalah tokoh sejarah Kerajaan Majapahit yang memiliki pengaruh besar dalam memperluas kekuatan Kerajaan Majapahit. Saat ini, tidak banyak visual karakter yang menampilkan latar sejarah Indonesia.

Studi ini menciptakan karakter Gajah Mada dalam konteks desain komunikasi visual. Mendesain pesan melalui elemen visual garis, bentuk, tekstur, dan warna. Sudi ini menunjukkan bahwa desain kostum pada karakter sebagai representasi makna informasi tentang dorongan kebangsawanan. Desain wajah dan postur sebagai representasi eleganitas dan kekuatan karakter dalam makna imaji. Hasil desain karakter ini diharapkan bisa memberi gambaran tentang tokoh sejarah di kerajaan Majapahit bagi remaja (Pratama dkk., 2018).

Desain karakter dapat dibuat melalui desain garis elemen, yang memvisualisasikan bentuk melalui tipe, ketebalan, orientasi, dan posisi, untuk menghadirkan kepribadian, ekspresi, identitas, dan emosi, gender, kelas sosial. Kemudian unsur-unsur bentuk untuk lebih memperkuat hubungan garis, dan dapat menyajikan penampilan karakter, tipe karakter, dan kepribadian (Pratama dkk., 2017).

Menurut Pratama dkk. (2017), kekuatan visual itu mampu membangun persepsi seseorang melalui elemen-elemen desain pada karakter visual. Pada akhirnya dapat dikatakan bahwa seseorang dapat melihat dan berpendapat mengenai suatu hal melalui karakter yang ia lihat tersebut.

\section{Bentuk dalam Karakter:}

Bentuk dapat membantu dalam sebuah perancangan karakter (Tillman, 2011).

1. Square

Umumnya saat melihat bentuk kotak, istilah yang seharusnya muncul adalah Stability, Trust, Honesty, Order, Conformity, Security, Equaliy, Masculiniy. Hal tersebut adalah hal terumum yang biasanya dipikirkan oleh seseorang jika melihat bentuk kotak. Penting untuk mengetahui informasi seperti ini saat membuat karakter karena kita tidak ingin memberikan arti yang tidak benar.

2. Triangle

Bentuk segitiga merupakan menyampaikan istilah action, Aggressio, energy, sneakiness, conflict, Tension.

3. Round

Lingkaran dapat dilihat sebagai Completeness, Gracefulness, Playfulness, Comforting, Unity, Protection Childlike. Bentuk tidak hanya berperan dalam bentuk wajah karakter namun berguna untuk bentuk tubuh juga. 


\section{Expresi dalam bentuk Karakter}

Mata dan wajah adalah kunci utama dari sebuah ekspresi. Menurut Thomas (1981) dijelaskan bahwa, mata adalah bagian terpenting dalam ekspresi dan harus digambarkan dengan ekspresi hati - hati. Sedikit gerakan tak beraturan atau gerakan yang salah diantaranya menghancurkan baik komunikasi dan kepercayaannya. Penonton melihat matanya, dan inilah dimana waktu dan uang harus dihabiskan jika karakternya diminta untuk bertingkah meyakinkan. Disney telah menemukan bertahun - tahun bahwa hubungan tertentu membuat ekspresi terbaca. Tidak ada bagian dari ekspresi, baik mata, atau bagian tersendiri lainnya dapat berkomunikasi jika sebuah ekspresi tidak bekerja sama.

\section{Perancangan Karakter}

Berikut adalah gambaran tokoh karakter Gajah Mada yang merupakan Patih Amangkubhumi yang berperan penting dalam puncak kejayaaan kerajaan Majapahit. Tokoh Gajah Mada akan ditampilkan dalam sebuah cerita berupa film animasi. Kejayaan Majapahit tak lepas dari jasa Mahapatih Amangkubhumi Gajah Mada, dengan "Sumpah Palapa". Patih Amangkhubumi atau yang disebut sebagai Gajah Mada mempunyai ciri-ciri karakter, seperti bima, seorang yang sangat berwibawa dengan badan yang sangat tinggi dan besar, memiliki jiwa yang sangat gagah berani, sehingga disegani oleh masyarakat.

Berikut adalah tokoh karakter Gajah Mada dengan bentuk berupa patung yang terdapat di Mojokerto, Jawa Timur. Tempat tersebut merupakan tempat kerajaan Majapahit berdiri.

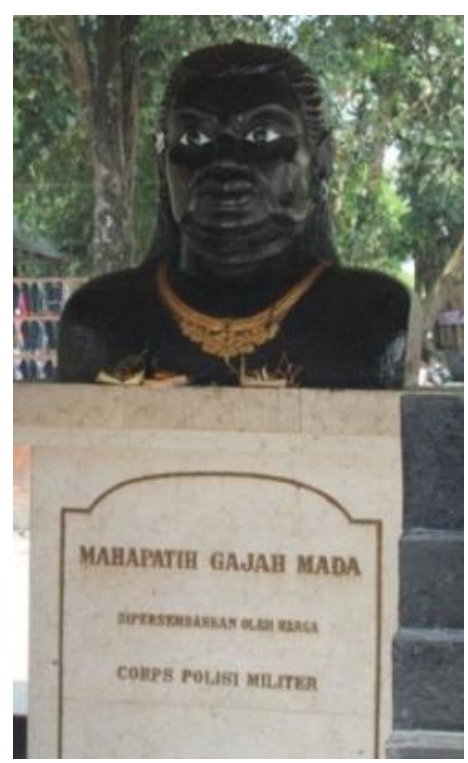

Gambar 1 Gajah Mada

Sumber: Alpiyah, 2018

Berikut merupakan rancangan desain visual karakter Gajah Mada yang dibuat oleh penulis. Tokoh Gajah Mada dibuat, yang akan berperan menjadi tokoh penting di film animasi "Kejayaan Majapahit". Di desain sedemikian rupa agar dapat menarik minat audience. Karakter ini dibuat dengan tampilan yang modern. 


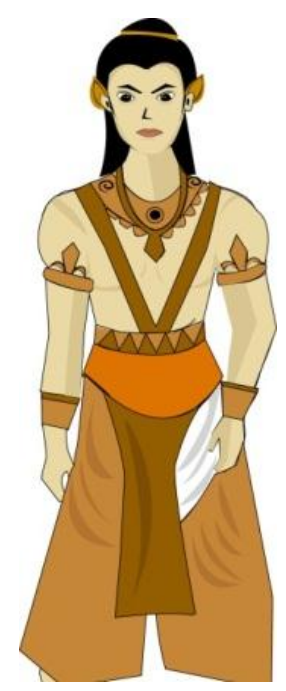

Gambar 2 Gajah Mada

Sumber: Alpiyah, 2018

\section{SIMPULAN}

Pembelajaran sejarah Kerajaan Majapahit yang cenderung konvensional setidaknya bisa dikemas lebih menarik melalui penggunaan media film animasi "Kejayaan Majapahit". Meski bisa dijadikan pembelajaran alternative, film animasi sebagai alat untuk menyampaikan sebuah informasi terkait sejarah kerajaan Majapahit pada puncak kejayaannya. Dengan demikian, film animasi sebagai alat bantu pembelajaran seharusnya tetap mempertahankan nilai-nilai sejarah, dan tidak harus memasukkan materi yang baku karena dapat mengakibatkan kegagalan penyampaian pesan dalam film animasi tersebut. Tujuannya adalah menjadikan film animasi sejajar dengan tujuan pembelajaran dan menambah wawasan yang sejajar dengan tujuan pembelajaran sejarah secara umum, yakni sebagai pembentuk karakter bangsa dengan memperkuat kesadaran sejarah kepada remaja yang akan menonton film animasi tersebut.

Dalam proses pembuatan film animasi tidak terlepas dari perancangan karakter tokoh. Karakter tokoh dapat menjadi ujung tombak keberhasilan sebuah film. Oleh sebab itu, pentingnya perancangan karakter tokoh, dalam hal ini tokoh Gajah Mada yang disesuaikan dengan segmenya. Dengan harapan, karakter tokoh tersebut dapat diterima oleh masyarakat dan berdampak pada pelestarian kebudayaan di Indonesia, khususnya tentang sejarah.

\section{DAFTAR PUSTAKA}

Adji, K. B. (2013). Majapahit: menguak Majapahit berdasarkan fakta sejarah. Yogyakarta: Araska.

Masmada, R. (2003). Gajah Mada sang pemersatu bangsa. Jakarta: Elex Media Komputindo.

Munandar, A. (2008). Ibu Kota Majapahit masa kejayaan dan pencapaian. Jakarta: Komunitas Bambu.

Nurhayati, E. (2018). Gajah Mada sistem politik dan kepemimpinan, Yogyakarta: Narasi.

Pratama, D., Wardani, W. G. W., \& Akbar, T. (2017). Designing visual character of Raden Wijaya as historical figure in visual novel. International Journal of Scientific \& Technology Research, 6(11), 207-210. 
Pratama, D., Wardani, W. G. W., \& Akbar, T. (2018). Designing visual elements of characters of Gajah Mada and Tribhuwana Tunggadewi as representation of historical figures in visual novel. Humanus, 17(01), 84-96.

Susilo, A., \& Sofiarini. (2018). Gajah Mada sang mahapatih pemersatu nusantara di bawah Majapahit tahun 1336-1359. Jurnal Pendidikan Sejarah dan Riset Sosial Humanoira (KAGANGA), 1 (1), 66-68.

Syahfitri, Y. (2011). Teknik film animasi dalam dunia komputer. Jurnal SAINTIKOM, 10(3), 213217.

Thomas, F., \& Johnston, O. (1981). The illusion of life: Disney animation. United State: Abbeville Press. 